\title{
UMA PROPOSTA LINGUÍSTICA DE CLASSIFICAÇÃO DOS CONSTITUINTES MORFOLÓGICOS QUE COMPÕEM OS SUBSTANTIVOS LATINOS
}

\section{A LANGUAGE PROPOSAL FOR CLASSIFICATION OF MORPHOLOGICAL CONSTITUENTS OF LATIN NOUNS COMPOSITION}

\begin{abstract}
Soraya Paiva Chain
RESUMO: Neste trabalho, apresentamos uma proposta linguística de classificação dos constituintes morfológicos que compõem os substantivos latinos, pois vemos que a maioria dos casos de cada declinação é composta de mais um constituinte, diferentemente de como as Gramáticas Latinas (GLs) os apresentam, constituídos somente de radical e desinência de caso. Primeiramente, apresentamos uma abordagem estruturalista, acerca dos tipos de morfemas constituintes dos nomes, a qual nos subsidia durante nossas análises. Em seguida, apresentamos quatro GLs e a forma como elas apresentam os constituintes morfológicos dos substantivos das cinco declinações, para, em comparação com a nossa proposta, demonstrarmos as diferenças. Depois, apresentamos nossa proposta, demonstrando que a maioria dos casos latinos de todas as declinações é composta de morfema lexical, morfema classificatório ou vogal de ligação e morfema categórico, comparando com a forma apresentada pelas GLs. Por fim, apresentamos algumas observações feitas a partir das nossas análises.
\end{abstract}

PALAVRAS-CHAVE: Estruturalismo; Morfologia; Morfema; Desinência; Caso

ABSTRACT: In this work, we present a linguistic proposal of classification of the morphological constituents that make up Latin nouns, as we see that most cases of each declension are composed of another constituent, unlike how the Latin Grammars (GLs) present them; consisting only of radical and case endings. First, we present a structuralist approach to the types of constituent morphemes of names, which subsidizes us during our analyses. Next, we present four GLs and how they present the morphological constituents of the nouns of the five declensions so that, in comparison with our proposal, we demonstrate the differences. Then, we present our proposal, showing that most Latin cases of all declensions are composed of a lexical morpheme, classifying morpheme or link vowel and categorical morpheme, compared with the form presented by GLs. Finally, we present some observations made from our analyses.

KEYWORDS: Linguistics, Structuralism; Morphology; Morpheme; Case

\footnotetext{
' Professora da Universidade Federal do Amazonas. Doutora em Linguística pela Universidade Federal de Santa Catarina. E-mail: sorayachain4@gmail.com
} 


\section{Introdução}

Os substantivos latinos são apresentados nas Gramáticas Latinas (GLs) em cinco declinações, de acordo com o tema que apresentam. Ou seja, os substantivos da primeira declinação têm tema em a, os da segunda declinação têm tema em $o$, os da terceira têm tema em $i$ ou em consoante, os da quarta declinação têm tema em $u$ e os substantivos da quinta declinação têm tema em e.

As GLs apresentam os substantivos em todos os casos, decompondo-os em radical e desinência de caso. Porém, sua estrutura morfológica constitui-se, na maioria dos casos de cada declinação, de radical, vogal temática/vogal de ligação e desinência de caso, mas isso não é mostrado pelos gramáticos latinos.

Pretendemos, com este estudo, apresentar uma proposta linguística de classificação dos constituintes morfológicos que compõem os substantivos latinos, com base na teoria estruturalista, que estuda a estrutura e a formação dos vocábulos, colocando os morfemas no centro da análise, para classificar todos os morfemas constituintes de cada caso de todas as declinações dos substantivos latinos.

As GLs, apesar de dizerem que os substantivos latinos são subdivididos em cinco declinações, pertencendo à esta, àquela ou àquela outra, de acordo com o tema que apresentam, não mostram em suas representações declinatórias a vogal temática ou a vogal de ligação, existente nas formas casuais. Representam morfologicamente os substantivos por meio de dois morfemas somente: radical e desinência de caso. O morfema que é representado como desinência de caso, por vezes, é a vogal temática apenas, outras, é a união da vogal temática com a desinência de caso, ou a união da vogal de ligação com a desinência de caso, e, poucas vezes, é de fato só a desinência de caso.

Ao dizerem que os substantivos latinos fazem parte de uma determinada declinação por conta do seu tema, e mostrarem a estrutura morfológica destes sem explicitar a vogal temática ou uma vogal de ligação, as GLs acabam por causar inquietação na mente dos estudantes. 
Considerando a forma como as GLs apresentam a constituição estrutural dos substantivos, apresentaremos nossa proposta linguística de classificação dos constituintes morfológicos que compõem os substantivos latinos, considerando tanto o que elas apresentam como desinências de caso, quanto o que elas falam a respeito da subdivisão dos substantivos em declinações, de acordo com o tema que apresentam. Utilizaremos dicionários latinos para observar e mostrar como os substantivos latinos são enunciados.

\section{Referencial teórico}

O Estruturalismo, nascido a partir das noções saussurianas de estrutura e sistema, tem Leonard Bloomfield como um dos principais representantes. É válido ressaltar que o Estruturalismo se dividira em duas correntes: europeia e americana.

Sobre sistema e estrutura, Costa (2015, p. 114) diz que

Saussure, o precursor do estruturalismo, enfatizou a ideia de que a língua é um sistema, ou seja, um conjunto de unidades que obedecem a certos princípios de funcionamento, constituindo um todo coerente. À geração seguinte coube observar mais detalhadamente como o sistema se estrutura: daí o termo "estruturalismo" para designar a nova tendência de se analisar as línguas.

Bloomfield, um dos estudiosos da geração posterior à Saussure, é considerado o fundador da linguística estrutural norte-americana, que era também conhecida como distribucionista, por trabalhar por etapas as análises que faziam do corpus selecionado.

\footnotetext{
O corpus apresenta-se em forma de enunciados lineares, conjuntos complexos que se reduzirão a diferentes elementos que se organizam em diferentes níveis. A língua apresenta uma série de ordens hierarquizadas (fonológica, morfológica frástica), em que cada unidade é definida pelas suas combinações no nível superior (DUBOIS, 1973, p. 48).
}

No Estruturalismo americano, estudava-se uma língua a partir de um corpus largamente variado, colhido efetivamente de falantes da língua estudada, em uma determinada época (sincronia), para descrever as regularidades observadas na língua por meio desse corpus. 
Esse método de análise, em que primeiramente são analisados os dados (reais) para depois serem criadas as regras, é conhecido como indutivo, ou seja, método indutivo é aquele que, após considerar um número suficiente de casos individuais, pode-se concluir (constituir) verdades (regras) gerais.

[...] para partir indutivamente do mínimo para o máximo, o vocábulo não é o termo inicial que se impõe. Ele se analisa ou decompõe, em formas mínimas constituintes, que são os «morfemas». [...] Saussure e seus discípulos e logo depois Bloomfield retomaram a tradição sincrônica e passaram a entender os morfemas como os elementos constitutivos atuais do vocábulo, sejam eles ou não elementos simples indivisíveis originários (CAMARA JÚNIOR, 2008, p. 22).

Pelo que se apresenta, uma análise distribucional é feita por etapas. No caso da análise do vocábulo - nível morfológico -, há de se considerar duas etapas: em uma primeira, observa-se a classe de cada palavra; e, na segunda, os morfemas que a compõe.

Como vamos analisar a estruturação morfológica dos substantivos latinos, faz-se necessário dizer que vamos trabalhar com palavras, que também são vocábulos, pois apresentam significado lexical (MONTEIRO, 2002, p. 12) e, como palavras, são formas livres, pois podem existir sozinhas em um enunciado (CAMARA JÚNIOR, 2008, p. 69).

Os substantivos - palavras - constituem-se, todos, como formas livres, por apresentarem significado lexical e, alguns, por serem formas indivisíveis em unidades morfológicas menores, ou seja, palavras simples. Há também substantivos que se compõem com "duas ou mais formas presas [...] ou de uma forma livre e uma ou mais formas presas" (Ibidem, p. 69, 70).

Forma presa é todo

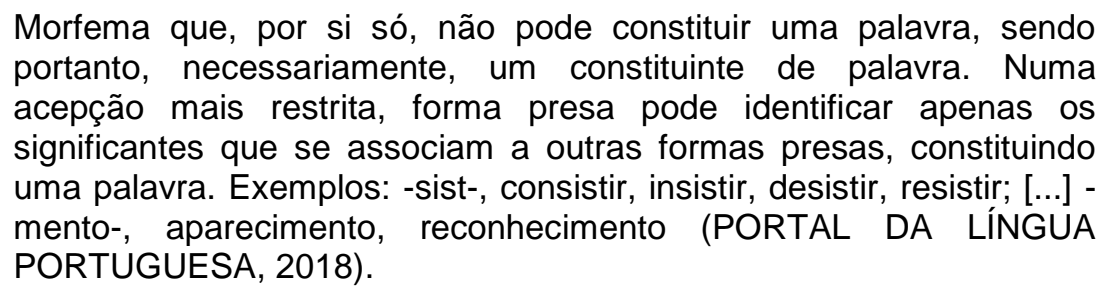

Os substantivos latinos flos, nomina e agri (flor, nome e campo), formas livres por apresentarem significado lexical, são constituídos de formas presas (flo-s; nomin-a; agr-I), ou seja, morfemas que por si só não constituem palavra. 
Por sua vez, os substantivos latinos nox, mulier e homo (noite, mulher e homem) são formas livres, tanto por apresentarem significado lexical, quanto por serem palavras simples, ou seja, não se subdividem em unidades morfológicas menores. Já os substantivos puero, animali e viris (menino, animal e varão), formas livres por apresentarem significado lexical, são constituídos de forma livre (puer; animal; vir) e forma presa (-o; -i; -is).

Como vemos, há um elemento constitutivo das palavras, que conhecemos como $\mathrm{raiz}^{1} / \mathrm{radical}^{2}$, que, a depender da palavra, pode se apresentar como forma livre ou presa. Como vemos também, há outro elemento constitutivo das palavras, que conhecemos como afixos, que sempre serão formas presas. Sobre os elementos constitutivos das palavras, Basílio (2007, p. 15) aduz que

Temos dois tipos de formativos mínimos, ou morfemas, na constituição da palavra: afixo e raiz. Raiz é um morfema que pode, por si só, constituir a base ou núcleo de uma palavra. Por exemplo, em luzir, luz é raiz. Os elementos que se acrescentam à raiz para formar uma palavra são chamados de afixos.

Sabemos que os afixos são morfemas que se unem ao radical das palavras para apresentar-lhes um novo sentido e, a depender da posição em que se apresentam em relação ao radical, antes ou depois, recebem, respectivamente, as denominações de prefixos e sufixos. Kehdi (2007, p. 27), afirma que

[...] a diferença entre prefixos e sufixos não é meramente distribucional. O acréscimo de um prefixo não contribui para a mudança de classe do radical a que se atrela, diferentemente do que ocorre com os sufixos, conforme se pode observar nos exemplos [...] leal, adjetivo, com [...] -dade, passa a substantivo: lealdade. [...] firmemente. [...] O sufixo pode, também, não alterar a classe gramatical do radical a que se junta; observe-se o exemplo ferreiro (subst..), derivado de ferro (subst.).

\footnotetext{
${ }^{1}$ Designação, vinculada à perspectiva diacrônica, para o elemento constituinte de palavra que contém o significado lexical básico, considerando as raízes da língua estudada. Ou seja, em comer o radical é com-, já a raiz é ed- do verbo latino eděre (KEHDI, 2007, p. 8 e 27).

2 Designação, vinculada à perspectiva sincrônica, para o elemento constituinte de palavra que contém significado lexical básico, inclui a raiz e é comum às palavras de uma mesma família (Idem, ibidem).
} 
Em nosso estudo, vamos: optar pelo uso do termo radical para designar a parte da palavra que é irredutível e comum às palavras de uma mesma família; e enfatizar a apresentação de alguns afixos que se apresentam depois do radical: vogal temática, vogal de ligação e desinência de caso. Esta última, também inclui a designação de número.

Radical, vogal temática e desinência de caso são morfemas, respectivamente, morfema lexical, morfema classificatório e morfema categórico. Monteiro (2002, p. 15) diz que o morfema lexical "constitui o núcleo semântico da palavra, e [...] é a parte comum a um grupo de palavras aparentadas pelo vínculo de significação. Assim, [caval] em: cavalo, cavalar, cavalariça, cavalaria, cavaleiro [...]".

Durante nossas análises, veremos que na declinação de um substantivo latino, o morfema lexical (radical), que a depender da declinação pode apresentar um alomorfe, repete-se em todos os casos.

Antes de falarmos sobre o morfema classificatório, é válido ressaltar que alomorfia, segundo Laroca (2003, p. 29),

[...] é a propriedade de um morfema ser representado por vários morfes denominados alomorfes. Os alomorfes são morfes que têm uma distintividade fonético-semântica comum, pois representam o mesmo morfema. Tomemos como exemplo o morfema \{plural\}, identificado graficamente através dos alomorfes - $s$ e -es dos seguinte dados: [...] canetas luzes \{plural\} / -s -es /. O sinal quer dizer "ou", "alternando-se com". Os alomorfes são, portanto, morfes alternantes que representam o mesmo morfema em contextos diferentes.

Exemplo de alomorfes em substantivos latinos, podemos verificar em ager, agri (campo) e populus, populi (população). Tomando como exemplo o morfema \{lexical\}, do primeiro substantivo acima, identificamos graficamente os alomorfes ager e agr-. Tomando como exemplo o morfema nominativo singular (masculino/feminino)\}, dos substantivos acima, identificamos graficamente 0 alomorfe -us em populus e o espaço vazio em ager, forma livre, tanto por apresentar significado lexical, quanto por ser palavra simples, ou seja, não se subdivide em unidades morfológicas menores.

\footnotetext{
${ }^{3}$ Apresentamos o substantivo da forma como são enunciados, ou seja, pelas formas de nominativo e genitivo, respectivamente.
} 
O espaço vazio, a que nos referimos acima, configura-se como uma ausência significativa (logo, morfema zero, o qual vamos representar por $\varnothing$ ), ou seja, falta de morfe (marca/desinência), que se opõe a outro seguimento no paradigma analisado, tendo o $\varnothing$ de ager contrapondo-se ao -us de populus.

De acordo com o que Kehdi (2007, p. 24) apresenta sobre morfema $\varnothing$, satisfazemos as condições, com as verificações feitas acima, para apontar o morfema $\varnothing$ em ager. Ele diz que

Só podemos postular um morfema $\varnothing$ se três condições forem satisfeitas: 1) é preciso que o morfema $\varnothing$ corresponda a um espaço vazio; 2) esse espaço vazio deve opor-se a um ou mais seguimentos (no par utilizado, o Ø de falava contrapõe-se ao -mos de falávamos); 3) a noção expressa pelo morfema $\varnothing$ deve ser inerente à classe gramatical do vocábulo examinado. Em nosso exemplo, as noções de número e pessoa existem obrigatoriamente em qualquer forma verbal portuguesa.

Quando se fala em oposição no paradigma, lembramos de uma das quatro famosas dicotomias saussurianas: sintagma versus paradigma ${ }^{4}$. Ao nosso estudo, interessa enfatizarmos o eixo paradigmático, no qual se dão as relações associativas, feitas a partir de uma série de elementos linguísticos capazes de figurar no mesmo ponto do eixo paradigmático, apenas uma por vez.

Faremos a classificação dos constituintes morfológicos dos substantivos latinos mediante a observação/identificação de seus morfemas no eixo paradigmático, local onde é feita a seleção do morfema (no caso, de palavras) que ocupará esse lugar/ponto/eixo.

Passemos agora ao morfema classificatório, que é

[...] uma espécie bastante discutida de morfema. Trata-se daqueles que nada parecem acrescentar ao significado do vocábulo, mas servem para definir sua estrutura, se nominal ou verbal. Seriam, então, os morfemas classificatórios, identificados pela vogal temática (Idem, p. 17)

A vogal temática dos substantivos latinos, não evidenciada como um dos constituintes da palavra nas representações declinatórias, como já dissemos,

\footnotetext{
${ }^{4}$ Saussure não usava o termo paradigma, ele usava associação. Os termos paradigma e sintagma foram cunhados pelos seus sucessores.
} 
foi um dos motivos que nos levaram a apresentar esse estudo. Em nossa análise, evidenciaremos a sua presença nas formas/casos em que ela aparece.

Por último, mas não menos importante, temos que atentar para os morfemas categóricos, sobre os quais Monteiro (Ibidem, p. 16) afirma que

\section{[...] não criam novas palavras. Apenas indicam as flexões que as formas assumem. [...] Os morfemas categóricos podem, pois, ser denominados de morfemas flexionais ou morfemas gramaticais. Sua função é a de permitir que as formas se apresentem nas diversas categorias próprias dos nomes ou dos verbos.}

Pelo que está posto, o termo categoria se refere à flexão e, como vamos trabalhar com flexão/declinação dos substantivos latinos, entendemos que os morfemas casuais latinos são categóricos, pois declinar é o mesmo que flexionar.

Por fim, como alguns substantivos latinos da terceira declinação são atemáticos (de tema consonantal), eles se constituem com vogal de ligação, que vem a ser um fonema (som vocálico) apresentado entre dois morfemas com finalidade tanto de facilitar a pronúncia quanto de apresentar a palavra de acordo com o padrão silábico da língua. Monteiro (2002, p. 49) diz que as vogais de ligação são morfes vazios, ou seja, não carregam nenhuma significação, logo não se configuram jamais como morfemas.

Com base nos conceitos apresentados aqui, vamos basear nossas análises, porém, antes do capítulo de análise, vamos demonstrar como os substantivos são apresentados nas GLs.

\section{A apresentação dos substantivos nas Gramáticas Latinas}

Vamos aqui mostrar como as GLs apresentam os substantivos para, em seguida, apresentarmos nossa proposta de classificação dos constituintes morfológicos que os compõem.

Optamos por selecionar quatro obras de autores distintos, para demonstrarmos como a estruturação dos substantivos é nelas apresentada: Gramática latina (1987), de Antônio Freire; Gramática básica do latim (1997), de Oswaldo A. Furlan \& Raulino Bussarello; Introdução à teoria e prática do 
latim (2000), de Janete Melasso Garcia; Compêndio de gramática latina (2003), de Maria Ana Almendra \& José Nunes de Figueiredo.

As quatro obras que selecionamos começam a apresentar os substantivos da primeira declinação informando que eles apresentam tema em a. E todas também apresentam as desinências casuais da primeira declinação, conforme o quadro ${ }^{5}$ abaixo:

Quadro 1 - Desinências de caso da primeira declinação

\begin{tabular}{|c|c|c|c|c|}
\hline CASO & $\mathrm{N}^{0}$ & DESINÊNCIAS & $\mathrm{N}^{0}$ & DESINÊNCIAS \\
\hline NOMINATIVO (N) & \multirow{6}{*}{ 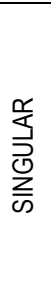 } & A & \multirow{6}{*}{ 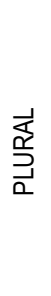 } & $A E$ \\
\hline GENITIVO (G) & & $\mathrm{AE}$ & & ARUM \\
\hline DATIVO (D) & & $\mathrm{AE}$ & & IS \\
\hline ACUSATIVO (Ac) & & AM & & AS \\
\hline VOCATIVO (V) & & A & & $A E$ \\
\hline ABLATIVO (Ab) & & A & & IS \\
\hline
\end{tabular}

Em relação aos substantivos da segunda declinação, as quatro GLs que selecionamos informam que os substantivos dessa declinação têm tema em 0 . Como a segunda declinação apresenta nomes em -us, em er/ir e em -um ${ }^{6}$ (terminações do nominativo singular para, respectivamente, masculinos/femininos, masculinos e neutros), as quatro obras apresentam da mesma forma as desinências casuais para os nomes em -us e em -um, conforme quadro abaixo, porém distinguem-se em relação à apresentação da constituição da forma de nominativo singular dos nomes em er/ir.

Quadro 2 - Desinências de caso da segunda declinação

\begin{tabular}{|c|c|c|c|c|c|c|c|c|}
\hline CASO & $\mathrm{N}^{0}$ & $\begin{array}{l}\text { DESINÊNCIAS } \\
\text { (nomes em -us) }\end{array}$ & $\mathrm{N}^{0}$ & $\begin{array}{l}\text { DESINÊNCIAS } \\
\text { (nomes em -us) }\end{array}$ & $\mathrm{N}^{0}$ & $\begin{array}{l}\text { DESINÊNCIAS } \\
\text { (nomes em -um) }\end{array}$ & $\mathrm{N}^{0}$ & $\begin{array}{l}\text { DESINÊNCIAS } \\
\text { (nomes em -um) }\end{array}$ \\
\hline $\mathrm{N}$ & \multirow{6}{*}{ 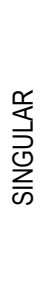 } & US & \multirow{6}{*}{ 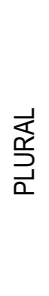 } & I & \multirow{6}{*}{ 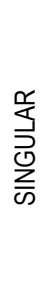 } & UM & \multirow{6}{*}{ 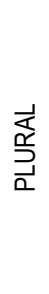 } & A \\
\hline G & & 1 & & ORUM & & 1 & & ORUM \\
\hline D & & 0 & & IS & & 0 & & IS \\
\hline Ac & & UM & & OS & & UM & & A \\
\hline V & & $E$ & & I & & UM & & A \\
\hline$A b$ & & 0 & & IS & & 0 & & IS \\
\hline
\end{tabular}

Fonte: dados da pesquisa

\footnotetext{
${ }^{5}$ Os quadros de 1 a 6 foram elaborados com base nas quatro obras, de autores distintos, selecionadas para demonstrarmos como a estruturação dos substantivos é nelas apresentada. ${ }^{6}$ Apresentamos tanto a terminação - us, quanto a terminação - um com hífen, por se tratarem de formas presas, ao contrário da apresentação das terminações er/ir, sem hífen, que se tratam de parte do radical da palavra.
} 
A respeito dos constituintes do nominativo dos nomes em er/ir, Freire (1987, p. 21) apresenta a declinação dos substantivos liber, libri e puer, pueri com a forma de nominativo como são enunciadas, ou seja, liber e puer, noutras palavras, sem separação morfêmica, porém também sem indicação e fala alguma sobre morfema $\varnothing$; Almendra \& Figueiredo (2003, p. 30 e 31) apresentam a declinação de ager, agri, separando a forma de nominativo (ag er) demonstrando, dessa forma, que ag-é radical e -er é desinência de caso. Noutro momento diz que agro- é o tema desse substantivo; Garcia (2000, p 5153) apresenta a declinação dos substantivos puer, pueri e ager, agri, demonstrando ao lado da forma do nominativo de ambos substantivos, como são enunciados, o morfema $\varnothing$, antes disso informa que a desinência de nominativo singular é $\varnothing$. Além disso, diz que ager, agri apresenta "um nominativo com alternância no radical, ou seja, um radical desenvolvido" e puer, pueri possui "nominativo com radical puro"; Furlan \& Bussarello (1997, p. 25) apresentam a declinação do substantivo puer, pueri da mesma forma que Freire, com a forma de nominativo como é enunciada, puer, porém, diferentemente dele, Furlan \& Bussarello falam da falta da desinência (morfema $\varnothing)$ no nominativo dos nomes em ere ir.

As quatro obras apresentam as desinências dos outros casos dos nomes em er/ir iguais às dos nomes em -us, informados na tabela acima, com exceção do vocativo singular, que, nos nomes em er/ir, são iguais ao nominativo singular.

A respeito dos substantivos da terceira declinação, as quatro GLs selecionadas informam que essa declinação se subdivide em consonantal e em vocálica, apresentando nomes de tema em consoante e nomes de tema em $i$. Todas as obras também, de forma diferente, informam sobre a variedade de terminações do nominativo singular que essa declinação apresenta.

As obras, com exceção de algumas observações específicas que vamos pontuar em seguida, apresentam as desinências dos casos da terceira declinação para palavras masculinas e femininas, conforme o quadro 3 e para palavras neutras conforme o quadro 4. 
Quadro 3 - Desinências de caso da terceira declinação para masculino e feminino

\begin{tabular}{|c|c|c|c|c|c|c|c|c|}
\hline CASO & $\mathrm{N}^{0}$ & $\begin{array}{l}\text { DESINÊNCIAS } \\
\text { (consonantal) }\end{array}$ & $\mathrm{N}^{0}$ & $\begin{array}{c}\text { DESINÊNCIAS } \\
\text { (consonantal) }\end{array}$ & $\mathrm{N}^{0}$ & $\begin{array}{l}\text { DESINÊNCIAS } \\
\text { (vocálica) }\end{array}$ & $\mathrm{N}^{\circ}$ & $\begin{array}{c}\text { DESINÊNCIAS } \\
\text { (vocálica) }\end{array}$ \\
\hline $\mathrm{N}$ & \multirow{6}{*}{$\begin{array}{l}\text { 㐍 } \\
\text { 总 } \\
\frac{\sum}{\infty}\end{array}$} & (várias) & \multirow{6}{*}{$\begin{array}{l}\overrightarrow{\vec{\alpha}} \\
\stackrel{\underline{s}}{د} \\
\vec{a}\end{array}$} & ES & \multirow{6}{*}{ 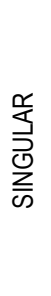 } & (várias) & \multirow{6}{*}{$\begin{array}{l}\text { 卒 } \\
\text { 竞 } \\
\text {. }\end{array}$} & ES \\
\hline G & & IS & & UM & & IS & & IUM \\
\hline D & & I & & IBUS & & I & & IBUS \\
\hline$A C$ & & EM & & ES & & EM & & ES \\
\hline V & & $=$ nominativo & & $=$ nominativo & & = nominativo & & $=$ nominativo \\
\hline$A b$ & & $E$ & & IBUS & & $\mathrm{E}$ & & IBUS \\
\hline
\end{tabular}

Fonte: dados da pesquisa

Quadro 4 - Desinências de caso da terceira declinação para palavras neutras

\begin{tabular}{|c|c|c|c|c|c|c|c|c|}
\hline CASO & $\mathrm{N}^{0}$ & $\begin{array}{c}\text { DESINÊNCIAS } \\
\text { (consonantal) }\end{array}$ & $\mathrm{N}^{0}$ & $\begin{array}{c}\text { DESINÊNCIAS } \\
\text { (consonantal) }\end{array}$ & $\mathrm{N}^{0}$ & $\begin{array}{l}\text { DESINẾNCIAS } \\
\text { (vocálica) }\end{array}$ & $\mathrm{N}^{0}$ & $\begin{array}{c}\text { DESINÊNCIAS } \\
\text { (vocálica) }\end{array}$ \\
\hline $\mathrm{N}$ & \multirow{6}{*}{ 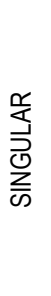 } & (várias) & \multirow{6}{*}{ 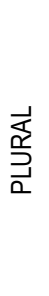 } & A & \multirow{6}{*}{ 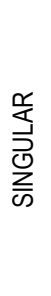 } & (várias) & \multirow{6}{*}{ 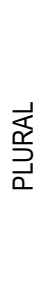 } & IA \\
\hline G & & IS & & UM & & IS & & IUM \\
\hline D & & I & & IBUS & & I & & IBUS \\
\hline$A c$ & & $=$ nominativo & & $\mathrm{A}$ & & $=$ nominativo & & IA \\
\hline V & & $=$ nominativo & & A & & $=$ nominativo & & IA \\
\hline$A b$ & & $E$ & & IBUS & & I & & IBUS \\
\hline
\end{tabular}

Fonte: dados da pesquisa

Garcia (2000, p. 74-75) fala a respeito das palavras de tema em $i$ e apresenta o substantivo ciuis, ciuis declinado em todos os casos e, exclusivamente no nominativo singular e no genitivo plural apresenta-os, respectivamente, (ciu i s) e (ciu i um), demonstrando radical, vogal temática e desinência casual. Também mostra a declinação completa de nubes, nubis e animal, animalis e, exclusivamente no genitivo plural daquele, apresenta (nub i um) e, exclusivamente nos nominativo e genitivo plural deste, apresenta (animal i a; animal i um).

Uma observação importantíssima que só Garcia (Idem, p. 72) faz é a de que "o nominativo singular apresenta várias terminações sendo que sua desinência pode ser 0 (zero) ou -s". Unidas, essa observação mais a informação de que os substantivos de tema em consoante apresentam genitivo plural em -um e os de tema em $i$ apresentam genitivo plural em -ium, pode-se observar todos os constituintes dos substantivos em cada caso, através da análise destes no eixo paradigmático.

Furlan \& Bussarello (1997, p. 26-27) apresentam os substantivos rex, regis, uirtus, uirtutis, corpus, corporis, ciuis, ciuis, ars, artis e mare, maris (os três primeiros de tema consonantal e os três últimos de tema em $I$ ), declinados em todos os casos e, o nominativo destes, respectivamente, rex, uirtus, corpus, 
ciu-is, ar-s e mar-e e, noutro momento, fala a respeito dos "nomes de nominativo singular em -s ou -x", como se $0-x$ fosse desinência de caso, além de não apresentar, na declinação, o $-s$ como desinência de caso dos substantivos uirtus, corpus, ciuis (deste diz que a desinência é -is), no nominativo singular.

Freire (1987, p. 22-23) apresenta os substantivos labor, laboris, dux, ducis, corpus, corporis, onus, oneris e flumen, fluminis (de tema consonantal) e auis, auis, nubes, nubis, ars, artis e mare, maris (de tema em $I$ ), declinados em todos os casos e, o nominativo destes, respectivamente: labor, dux, corpus, onus, flumen, au-is, nub-es, ars e mar-e. Ou seja, não informa o -s como desinência de caso de nominativo dos substantivos corpus, onus, auis, nubes e ars, além de não falar nada a respeito de quais seriam de fato as desinências desse caso no singular. De auis e nubes apresenta, respectivamente, -is e -es como desinência de caso de nominativo singular.

Almendra \& Figueiredo (2003, p. 35-39) demonstram a declinação dos substantivos de terceira, bem como a apresentação do nominativo singular, da mesma forma que Freire, diferindo somente no uso de alguns substantivos diferentes.

Sobre os substantivos da quarta declinação, as quatro obras aqui relacionadas informam que os nomes dessa declinação apresentam tema em $u$, e todas apresentam as desinências de caso dessa declinação, conforme o quadro abaixo:

Quadro 5 - Desinências de caso da quarta declinação

\begin{tabular}{|c|c|c|c|c|c|c|c|c|}
\hline CASO & $\mathrm{N}^{0}$ & $\begin{array}{c}\text { DESINÊNCIAS } \\
\text { masc/fem }\end{array}$ & $\mathrm{N}^{0}$ & $\begin{array}{c}\text { DESINÊNCIAS } \\
\text { masclfem }\end{array}$ & $\mathrm{N}^{0}$ & $\begin{array}{c}\text { DESINÊNCIAS } \\
\text { Neutro }\end{array}$ & $\mathrm{N}^{0}$ & $\begin{array}{c}\text { DESINÊNCIAS } \\
\text { neutro }\end{array}$ \\
\hline $\mathrm{N}$ & \multirow{6}{*}{ 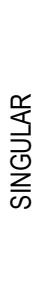 } & US & \multirow{6}{*}{ 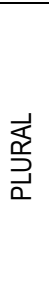 } & US & \multirow{6}{*}{ 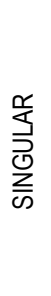 } & U & \multirow{6}{*}{$\begin{array}{l}\text { 卒 } \\
\text { 竞 }\end{array}$} & UA \\
\hline G & & US & & UUM & & US & & UUM \\
\hline $\mathrm{D}$ & & UI & & IBUS/UBUS & & UI & & IBUS/UBUS \\
\hline Ac & & UM & & US & & U & & UA \\
\hline V & & US & & US & & U & & UA \\
\hline$A b$ & & U & & IBUS/UBUS & & U & & IBUS/UBUS \\
\hline
\end{tabular}

Fonte: dados da pesquisa

Por fim, as quatro GLs que elencamos também coadunam em dizer que os nomes da quinta declinação apresentam tema em e, e, igualmente coadunam ao apresentarem as desinências de caso dessa declinação, conforme o quadro abaixo: 


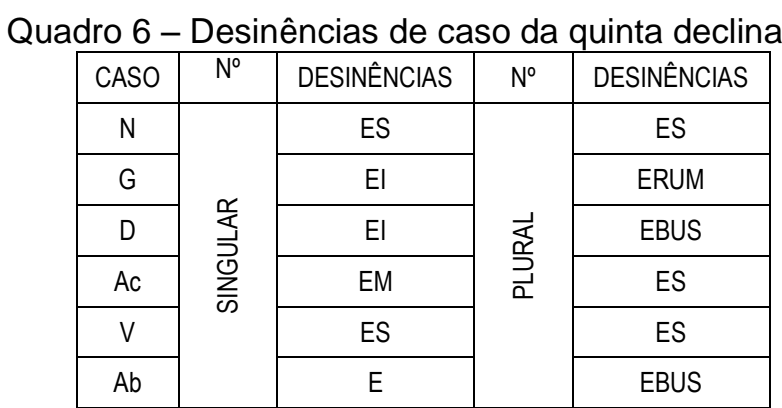

Fonte: dados da pesquisa

De acordo com o exposto, observamos que somente uma (Introdução à teoria e prática do latim, 2000), dentre as quatro obras que selecionamos, apresenta alguns detalhes em relação aos morfemas que se apresentam na constituição dos substantivos/casos latinos, e isso só se dá na apresentação da terceira declinação. É válido observar que, conforme falamos, todas as GLs são unânimes em dizer que cada declinação apresenta um tema, apesar de não demonstrarem a vogal temática, quando ela aparece nos casos de cada declinação, excetuando-se alguns casos da terceira declinação que Garcia (2003), conforme apresentamos, demonstra.

\section{Análise}

Vamos agora analisar substantivos de todas as declinações, declinados em todos os casos, para demonstrar todos os constituintes de cada caso.

Sabendo que tanto em nomes quanto em verbos, quando a vogal temática, morfema classificatório, é apresentada na palavra, ela aparece imediatamente após o radical, apresentando o tema da mesma. Como já vimos que os substantivos da primeira declinação apresentam tema em a, declinamos, abaixo, aqua, aquae, substantivo da primeira declinação, representando os gêneros masculino e feminino (únicos existentes nessa declinação), em todos os casos, para, através de análise paradigmática, demonstrarmos os constituintes existentes em cada caso. 
Quadro 7 - Declinação de aqua, ae

\begin{tabular}{|c|c|c|}
\hline \multirow{6}{*}{ 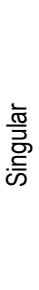 } & $\mathrm{N}$ & AQUA \\
\hline & $G$ & AQUAE \\
\hline & $D$ & AQUAE \\
\hline & $A c$ & AQUAM \\
\hline & V & AQUA \\
\hline & $A b$ & AQUA \\
\hline \multirow{6}{*}{ 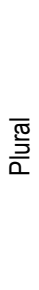 } & $\mathrm{N}$ & AQUAE \\
\hline & G & AQUARUM \\
\hline & $D$ & AQUIS \\
\hline & $A c$ & AQUAS \\
\hline & V & AQUAE \\
\hline & $A b$ & AQUIS \\
\hline
\end{tabular}

Fonte: dados da pesquisa

Observamos que aqu- se repete em todos os casos e, sabendo que se trata de uma palavra da primeira declinação, a qual apresenta tema em $a$, vemos que somente nos casos dativo e ablativo, no plural, a vogal temática não se apresenta. Com isso, podemos dizer que as palavras da primeira declinação, nesses dois casos, no plural, são constituídas somente de radical (morfema lexical) e desinência de caso (morfema categórico), e, nos demais casos, são constituídas de radical, vogal temática (morfema classificatório) e desinência de caso, conforme a apresentação no quadro abaixo.

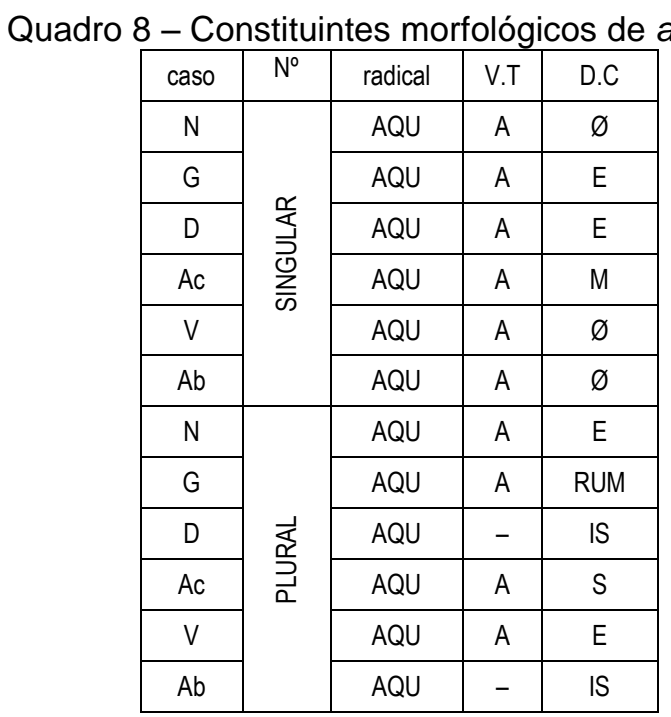

Fonte: dados da pesquisa

Também com a análise no paradigma, vimos que o substantivo aqua, aquae, declinado nos casos nominativo, vocativo e ablativo, no singular, é formado somente de radical e vogal temática. Por conta disso, apresentamos a 
ausência do morfe desses casos com o morfema $\varnothing$, pois sua ausência se opõe a outros seguimentos no paradigma analisado, fazendo-se significativa. Já no paradigma de apresentação da vogal temática, considerando que se trata de morfema classificatório, ou seja, que serve apenas para classificar as palavras como nominais ou verbais e nada acrescenta ao significado das palavras, apresentamos um traço para representar a ausência dela nos dois casos do plural já citados.

Comparando os quadros 8 e 1, podemos observar que as gramáticas latinas apresentam somente dois constituintes em todos os casos do substantivo declinado, apresentando a vogal temática como parte da desinência de caso, em todos os casos em que ela aparece.

Sabendo que os substantivos da segunda declinação apresentam tema em 0 , declinamos, abaixo ${ }^{7}$, populus, populi e ager, agri e oliuum, oliui (representando, respectivamente, masculinos/femininos, masculinos e neutros), em todos os casos, para, através de análise paradigmática, demonstrarmos os constituintes existentes em cada caso.

\begin{tabular}{|c|c|c|c|c|}
\hline \multirow{7}{*}{$\begin{array}{l}\frac{\bar{\pi}}{5} \\
\overline{\bar{\sigma}} \\
\frac{5}{5}\end{array}$} & caso & masc./fem. & masc. & neutro \\
\hline & $\mathrm{N}$ & POPULUS & AGER & OLIVUM \\
\hline & G & POPULI & AGRI & OLIVI \\
\hline & D & POPULO & AGRO & OLIVO \\
\hline & Ac & POPULUM & AGRUM & OLIVUM \\
\hline & V & POPULE & AGER & OLIVUM \\
\hline & $A b$ & POPULO & AGRO & OLIVO \\
\hline \multirow{6}{*}{ 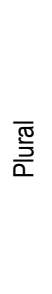 } & $\mathrm{N}$ & POPULI & AGRI & OLIVA \\
\hline & G & POPULORUM & AGRORUM & OLIVORUM \\
\hline & $\mathrm{D}$ & POPULIS & AGRIS & OLIVIS \\
\hline & $A c$ & POPULOS & AGROS & OLIVA \\
\hline & V & POPULI & AGRI & OLIVA \\
\hline & $A b$ & POPULIS & AGRIS & OLIVIS \\
\hline
\end{tabular}

Fonte: dados da pesquisa

Observamos que popul- e oliu- se repetem em todos os casos, ou seja, radical igual para todos os casos. Além disso, sabendo que os três substantivos são da segunda declinação, a qual apresenta tema em 0 , vemos

\footnotetext{
${ }^{7}$ Os quadros de 7 a 17 foram elaborados tanto com base no que as GLs apresentam quanto com base nos estudos que fizemos.
} 
que somente nos casos dativo e ablativo, no singular, e nos casos genitivo e acusativo, no plural, a vogal temática ocorre.

Em relação ao substantivo ager, agri, conforme já informado na nota 6, o er de ager é parte do radical do nominativo singular, concordando com o que Garcia (2000, p. 52-53) e Furlan \& Bussarello (1997, p. 25) apresentam. Observando os casos em que a vogal temática se apresenta, já citados acima, percebemos que, a depender do caso, o radical desse substantivo pode ser ager ou agr-.

Partindo dessas observações, apresentamos, no quadro abaixo, os constituintes que cada um desses substantivos apresenta em cada caso.

Quadro 10 - Constituintes morfológicos de populus, $i$, ager, agri e oliuum, $i$

\begin{tabular}{|c|c|c|c|c|c|c|c|c|c|c|}
\hline \multirow{8}{*}{$\frac{\stackrel{\bar{\pi}}{\bar{J}}}{\stackrel{\overline{5}}{\bar{\omega}}}$} & \multirow{2}{*}{$\begin{array}{l}\text { Oొ } \\
\text { ర్ల }\end{array}$} & \multicolumn{3}{|c|}{ masc. / fem. } & \multicolumn{3}{|c|}{ masc. } & \multicolumn{3}{|c|}{ neutro } \\
\hline & & radical & V.T & D.C & radical & V.T & D.C & radical & V.T & D.C \\
\hline & $\mathrm{N}$ & POPUL & U & S & AGER & _ & $\varnothing$ & OLIV & U & $M$ \\
\hline & G & POPUL & - & I & AGR & - & 1 & OLIV & - & I \\
\hline & $\mathrm{D}$ & POPUL & 0 & $\varnothing$ & AGR & 0 & $\varnothing$ & OLIV & 0 & $\varnothing$ \\
\hline & $A c$ & POPUL & $\mathrm{U}^{8}$ & M & AGR & U & M & OLIV & U & $M$ \\
\hline & V & POPUL & - & $E$ & AGER & - & $\varnothing$ & OLIV & U & M \\
\hline & $A b$ & POPUL & 0 & $\varnothing$ & AGR & 0 & $\varnothing$ & OLIV & 0 & $\varnothing$ \\
\hline & $\mathrm{N}$ & POPUL & _- & I & AGR & - & I & OLIV & - & $A$ \\
\hline & G & POPUL & 0 & RUM & AGR & 0 & RUM & OLIV & 0 & RUM \\
\hline 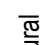 & $\mathrm{D}$ & POPUL & - & IS & AGR & - & IS & OLIV & - & IS \\
\hline $\bar{\alpha}$ & Ac & POPUL & 0 & S & AGR & 0 & $S$ & OLIV & - & $A$ \\
\hline & V & POPUL & - & 1 & AGR & - & 1 & OLIV & - & A \\
\hline & $A b$ & POPUL & - & IS & AGR & _- & IS & OLIV & - & IS \\
\hline
\end{tabular}

Fonte: dados da pesquisa

Chamamos a atenção para os constituintes do acusativo singular dos três substantivos e para o nominativo e vocativo singular de oliuum, oliui. Nestes casos, concluímos que a vogal u é um alomorfe da vogal temática 0 , sendo só $0 \mathrm{~m}$ a desinência de caso desses casos. Também no nominativo singular de populus, populi, apresenta-se a variante $u$ da vogal tema da declinação. Entendemos - u- como alomorfe da vogal temática: primeiro porque ela se apresenta no paradigma da vogal temática; segundo porque tanto na primeira declinação, da qual já apresentamos a análise, quanto nas demais declinações, as quais ainda vamos analisar, a desinência de acusativo singular

\footnotetext{
${ }^{8}$ Alomorfe da vogal temática.
} 
é sempre $m$ e, na maioria das declinações, a desinência de nominativo singular é $s$.

Comparando os quadros 10 e 2, percebermos que as gramáticas latinas fazem com os substantivos da segunda declinação o mesmo que fazem com os substantivos da primeira declinação, ou seja, apresentam somente dois constituintes em todos os casos do substantivo declinado, apresentando a vogal temática, quando ela ocorre, como parte da desinência de caso.

Conforme já vimos, os substantivos da terceira declinação podem apresentar tema em consoante ou em i. Declinaremos, abaixo, nox, noctis, mare, maris, uirtus, uirtutis e flumen, fluminis, (representando, respectivamente, masculinos/femininos e neutros com tema em $i$ e masculinos/femininos e neutros com tema em consoante), em todos os casos, para, através de análise paradigmática, demonstrarmos os constituintes existentes em cada caso.

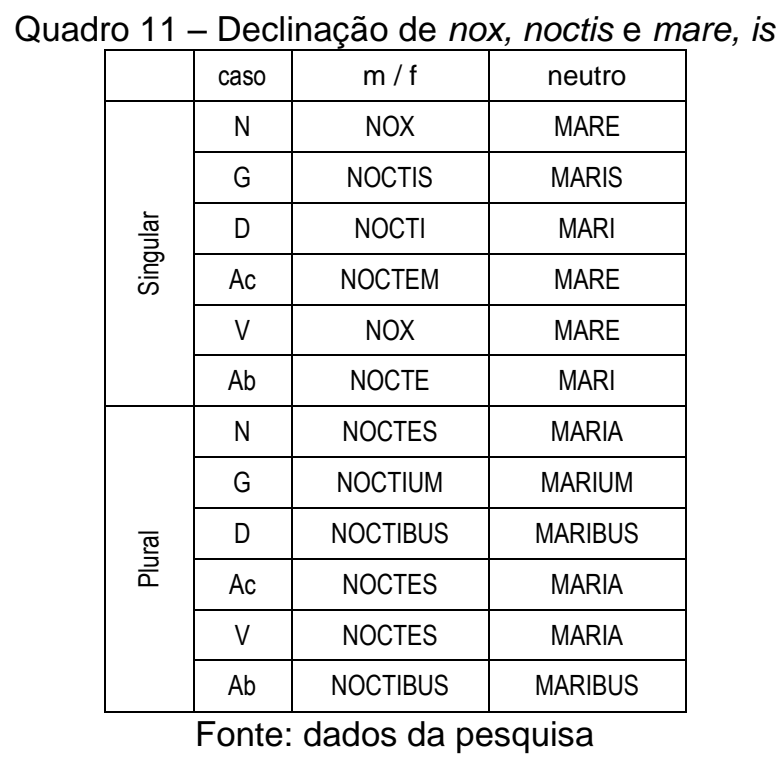

Com duas observações, sendo a primeira, a informação importantíssima, com a qual coadunamos, que só Garcia (2000, p. 72), dentre os quatro gramáticos latinos apresentados aqui, faz de que "o nominativo singular apresenta várias terminações sendo que sua desinência pode ser 0 (zero) ou s", e a segunda, a informação de genitivo, singular, apresentada nos dicionários e livros didáticos, seguida da forma de nominativo, para observarmos que, na maioria das palavras da terceira declinação, o radical do genitivo é mais desenvolvido do que o radical do nominativo, inferimos que 
noct- (forma presa) e nox (forma livre) são radicais do substantivo feminino nox, noctis, sendo, respectivamente, morfe e alomorfe do morfema lexical.

Como vemos que há duas formas representativas do mesmo morfema, ou seja, do morfema lexical, tomamos como base, para definir qual delas é morfe e qual é alomorfe, o critério estatístico, apresentado por Kehdi (2007, p. 21), que indica que "dentre as formas variantes, é escolhida como forma básica a mais frequente".

Em relação ao substantivo neutro mare, maris, vemos que mar- (forma livre) se repete em todos os casos, sendo ele o radical.

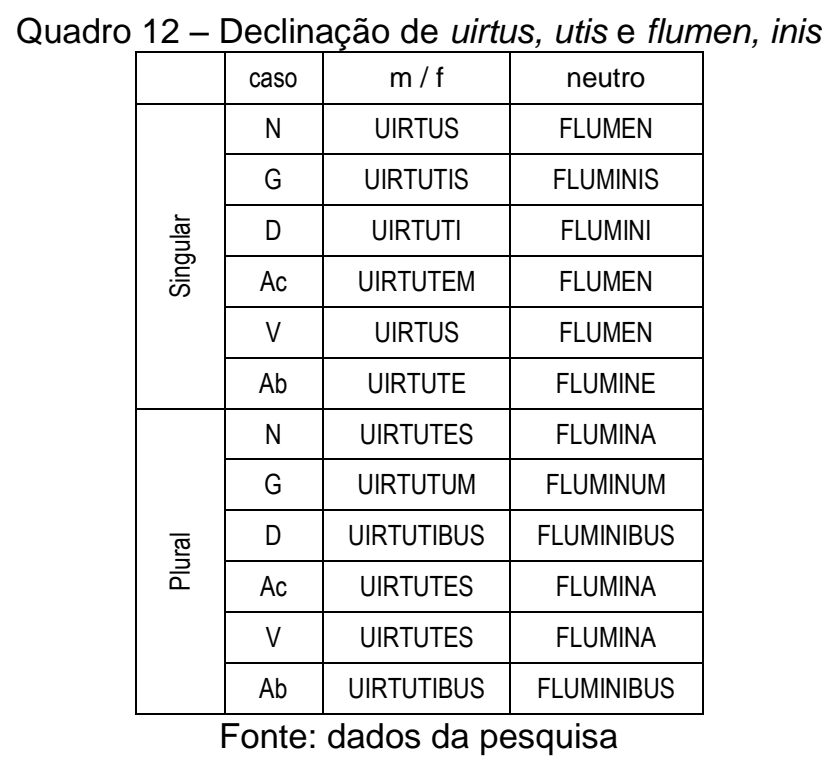

Vemos que, na declinação de uirtus, uirtutis, uirtu-se repete em todos os casos. Porém, considerando a forma desenvolvida de genitivo singular, em relação à forma de nominativo, vemos também que uirtut-, que é o radical do genitivo, também se repete em muitos casos.

Além disso, considerando que -s é desinência de caso do nominativo, inferimos, com base no critério estatístico já apresentado, que uirtut- é o morfe e uirtu- é alomorfe do morfema lexical.

Em relação ao substantivo flumen, fluminis, vemos em sua declinação que flumin-, forma presa, é radical de genitivo singular, ao passo que flumen, forma livre, constitui o nominativo singular. Também pelo critério estatístico, inferimos que este é alomorfe e aquele é o morfe, ambos são formas representativas do morfema lexical. 
Partindo dessas observações, apresentamos, no quadro abaixo, os constituintes que cada um desses substantivos apresenta em cada caso.

Quadro 13 - Constituintes morfológicos de nox, noctis, mare, is, uirtus, utis e flumen, inis

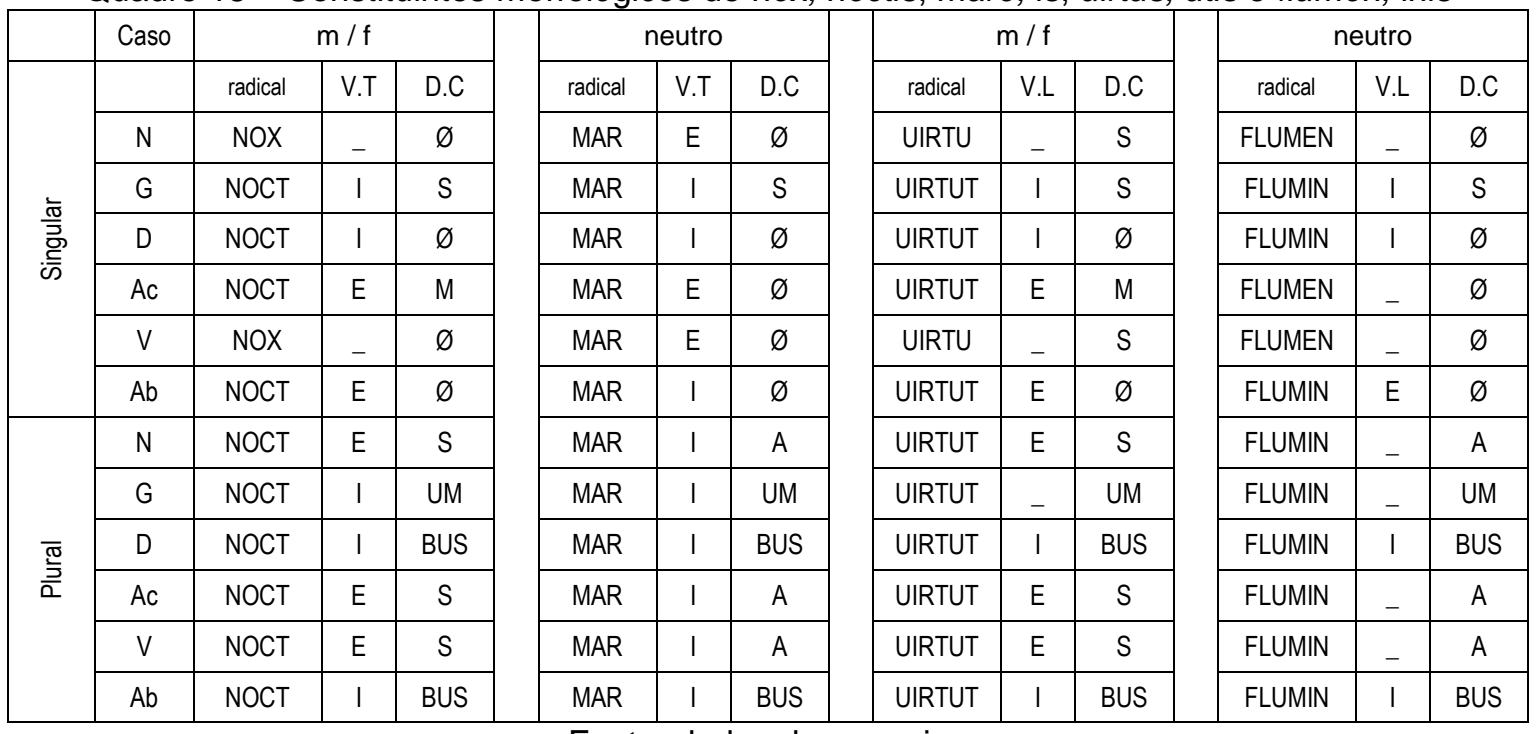

Fonte: dados da pesquisa

Sabendo que, de acordo com regras gramaticais, os substantivos do quadro 11 têm tema em $i$, observamos que, claramente, o tema (radical mais vogal temática) de nox, noctis é nocti-, apresentado nas formas de genitivo e dativo, singular, e genitivo, dativo e ablativo, plural. Já em mare, maris, o tema mari- é claramente apresentado nas formas de genitivo, dativo e ablativo, singular, e em todas as formas do plural.

Observando o paradigma da vogal temática, vemos que, em outros casos, no lugar do - $i$ - o -e- aparece. Como essa outra vogal aparece no mesmo paradigma da vogal temática, ou seja, imediatamente após o radical, e sendo esses substantivos temáticos, inferimos que esse -e- é um alomorfe da vogal temática.

Não podemos classificar as vogais -e e -i, que se apresentam após o radical dos substantivos do quadro 11, como vogais temáticas, pois esses, de acordo com regras gramaticais, têm tema em consoante, ou seja, são atemáticos. Sendo assim, inferimos que, nesse contexto, elas devem ser classificadas como vogais de ligação, pois, de acordo com Monteiro (2002, p. 49), são fonemas que se apresentam nas palavras para adequá-las ao padrão silábico da língua. 
Comparando o quadro 13 com os quadros 3 e 4, percebermos que as gramáticas latinas fazem com os substantivos da terceira declinação o mesmo que fazem com os substantivos das primeira e segunda declinações, ou seja, apresentam somente dois constituintes em todos os casos do substantivo declinado, apresentando a vogal temática ou a vogal de ligação, quando ocorre uma delas, como parte da desinência de caso.

De acordo com o que já vimos, os substantivos da quarta declinação apresentam tema em $u$. Declinamos, abaixo, manus, manus e genu, genus, substantivos que representam, respectivamente, os gêneros masculino/feminino e neutro, em todos os casos, para, através de análise paradigmática, demonstrarmos os constituintes existentes em cada caso.

\begin{tabular}{|c|c|c|c|}
\hline & caso & $m / f$ & neutro \\
\hline \multirow{6}{*}{ 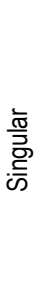 } & $\mathrm{N}$ & FRUCTUS & GENU \\
\hline & G & FRUCTUS & GENUS \\
\hline & $\mathrm{D}$ & FRUCTUI & GENU \\
\hline & Ac & FRUCTUM & GENU \\
\hline & V & FRUCTUS & GENU \\
\hline & $A b$ & FRUCTU & GENU \\
\hline \multirow{6}{*}{ 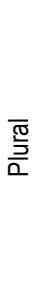 } & $\mathrm{N}$ & FRUCTUS & GENUA \\
\hline & G & FRUCTUUM & GENUUM \\
\hline & D & FRUCTIBUS & GENUBUS \\
\hline & $A c$ & FRUCTUS & GENUA \\
\hline & V & FRUCTUS & GENUA \\
\hline & $A b$ & FRUCTIBUS & GENUBUS \\
\hline
\end{tabular}

Fonte: dados da pesquisa

Observando o paradigma de ambos substantivos declinados, podemos verificar que em fructus, fructus, fructu- se repete em quase todos os casos e, em genu, genus, a forma que se repete em todos os casos é genu-. Sabendo que se tratam de substantivos com tema em $u$, inferimos que as formas fructue genu- são o tema.

Ainda analisando o paradigma, apresentamos, no quadro abaixo, ambos substantivos com todos os constituintes de cada caso classificados. 
Quadro 15 - Constituintes morfológicos de fructus, us e genu, us

\begin{tabular}{|c|c|c|c|c|c|c|c|}
\hline & & \multicolumn{3}{|c|}{ masc. / fem. } & \multicolumn{3}{|c|}{ neutro } \\
\hline & caso & radical & V.T & D.C & radical & V.T & D.C \\
\hline \multirow{6}{*}{$\begin{array}{l}\frac{\bar{\pi}}{\bar{\Xi}} \\
\frac{\bar{\sigma}}{\bar{c}}\end{array}$} & $\mathrm{~N}$ & FRUCT & U & S & GEN & U & $\varnothing$ \\
\hline & G & FRUCT & U & S & GEN & U & $S$ \\
\hline & D & FRUCT & U & I & GEN & U & $\varnothing$ \\
\hline & Ac & FRUCT & U & M & GEN & U & $\varnothing$ \\
\hline & V & FRUCT & U & S & GEN & U & $\varnothing$ \\
\hline & $A b$ & FRUCT & U & $\varnothing$ & GEN & U & $\varnothing$ \\
\hline \multirow{6}{*}{$\begin{array}{l}\overline{\frac{\pi}{丂}} \\
\overline{\bar{D}}\end{array}$} & $\mathrm{~N}$ & FRUCT & U & $S$ & GEN & U & $A$ \\
\hline & G & FRUCT & U & UM & GEN & U & UM \\
\hline & D & FRUCT & $1^{9}$ & BUS & GEN & U & BUS \\
\hline & $A c$ & FRUCT & U & S & GEN & U & $A$ \\
\hline & V & FRUCT & U & S & GEN & U & A \\
\hline & $A b$ & FRUCT & I & BUS & GEN & U & BUS \\
\hline
\end{tabular}

Fonte: dados da pesquisa

Pelo paradigma flexional, podemos ver que, nos dois casos (dativo e ablativo, plural) de fructus, fructus, em que o tema fructu- não se apresenta, ocorre uma outra marca, alomorfe, para o morfema classificatório, vogal temática, fazendo com que nesses dois casos do plural o tema se apresente em fructi-.

Comparando os quadros 15 e 5, percebermos que as gramáticas latinas fazem com os substantivos da quarta declinação o mesmo que fazem com os substantivos das primeira, segunda e terceira declinações, ou seja, apresentam somente dois constituintes em todos os casos do substantivo declinado, apresentando a vogal temática, quando ocorre, como parte da desinência de caso.

Conforme também já vimos, os substantivos da quinta declinação apresentam tema em e. Apresentamos, no quadro abaixo, res, rei, substantivo que representa os gêneros masculino e feminino (únicos possíveis nessa declinação), em todos os casos, para, através de análise paradigmática, demonstrarmos os constituintes existentes em cada caso.

\footnotetext{
${ }^{9}$ Alomorfe da vogal temática.
} 


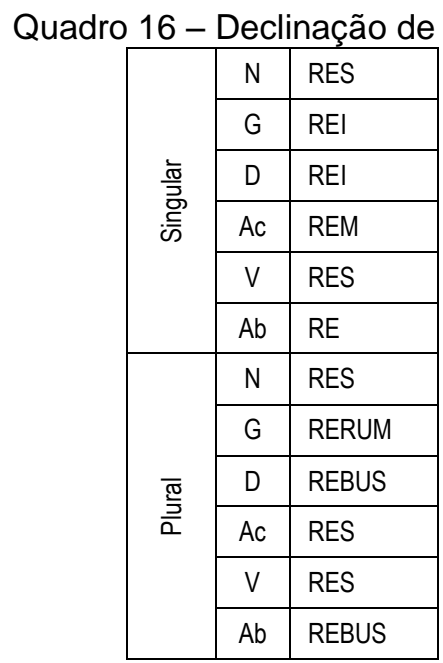

Fonte: dados da pesquisa

Com a declinação do substantivo res, rei, e sabendo que ele tem tema em e, podemos inferir que re-, que é a forma que se repete em todos os casos, é o tema.

Conforme análise no paradigma, apresentamos, no quadro abaixo, os constituintes de cada caso de res, rei.

\begin{tabular}{|c|c|c|c|c|}
\hline & caso & radical & V.T & D.C \\
\hline & $\mathrm{N}$ & $\mathrm{R}$ & $E$ & $S$ \\
\hline & G & $\mathrm{R}$ & $E$ & I \\
\hline$\frac{\frac{\pi}{3}}{2}$ & $D$ & $\mathrm{R}$ & $E$ & 1 \\
\hline ら & $A c$ & $\mathrm{R}$ & $E$ & $\mathrm{M}$ \\
\hline & V & $\mathrm{R}$ & $E$ & $S$ \\
\hline & $A b$ & $\mathrm{R}$ & $E$ & $\varnothing$ \\
\hline & $\mathrm{N}$ & $\mathrm{R}$ & $E$ & $S$ \\
\hline & G & $\mathrm{R}$ & $E$ & UM \\
\hline$\overline{\widetilde{0}}$ & D & $\mathrm{R}$ & $E$ & BUS \\
\hline & $A c$ & $\mathrm{R}$ & $E$ & $S$ \\
\hline & V & $\mathrm{R}$ & $E$ & $S$ \\
\hline & $A b$ & $\mathrm{R}$ & $\mathrm{E}$ & BUS \\
\hline
\end{tabular}

Fonte: dados da pesquisa

Como não se apresentam alomorfes para o morfema flexional (radical), nem para o morfema classificatório (vogal temática), muito tranquila é a verificação, no paradigma, dos morfemas categóricos dos substantivos de quinta declinação. 
Comparando os quadros 17 e 6, percebermos que as gramáticas latinas fazem com os substantivos da quinta declinação o mesmo que fazem com os substantivos das outras quatro declinações, ou seja, apresentam somente radical e desinência de caso, representando a vogal temática aglutinada à desinência de caso.

\section{Considerações Finais}

Conforme observado, os substantivos latinos de fato apresentam mais constituintes do que os apresentados pelas gramáticas latinas, que os decompõem somente em morfema lexical (radical) e morfema categórico (desinência de caso). Vimos que os substantivos, na maioria dos casos, em todas as declinações, são compostos de morfema lexical, morfema classificatório (vogal temática) ou vogal de ligação (que aparece especificamente em substantivos de tema consonantal da terceira declinação) e morfema categórico.

Por meio das análises apresentadas, além de evidenciarmos nossa proposta linguística de classificação dos constituintes morfológicos que compõem os substantivos latinos por meio dos quadros 8, 10, 13, 15 e 17, também podemos fazer algumas observações:

1. A vogal tema dos substantivos, em todas as declinações, quando ocorre, é apresentada, nas gramáticas latinas, como parte do morfema categórico (desinência de caso);

2. Em muitos casos, nas gramáticas latinas, a vogal temática assume sozinha a função gramatical de morfema categórico, quando, na verdade, o morfema categórico, nesses casos, deve ser representado por $\varnothing$, como vimos;

3. A desinência de caso do nominativo singular dos substantivos de todas as declinações é $s, \varnothing$ ou $m$, sendo o $m$ específico para palavras neutras da segunda declinação;

4. A desinência de caso do acusativo singular dos substantivos de todas as declinações de qualquer gênero é $m$;

5. A desinência de caso do genitivo plural dos substantivos das primeira, segunda e quinta declinações é rum, e das terceira e quarta é um; 
6. A desinência dos casos dativo e ablativo plural dos substantivos das primeira e segunda declinações é is, e das terceira, quarta e quinta é bus.

Por fim, é válido ressaltar que os substantivos de terceira declinação são designados como atemáticos (ou de tema consonantal) ou temáticos (de tema em i) por estarem em consonância, respectivamente, com a terceira conjugação verbal latina e com alguns verbos, considerados como de terceira conjugação mista, onde estes apresentam tema em $i$ e aqueles são atemáticos.

\section{Referências}

ALMENDRA, Maria Ana; FIGUEIREDO, José Nunes de. (2003). Compêndio de gramática latina. Coimbra: Ed. Porto, 2003.

BASILIO, Margarida. (2007). Teoria lexical. 8. ed. São Paulo: Ática, 2007.

CAMARA JÚNIOR, Joaquim Mattoso. (2008). Estrutura da língua portuguesa. 41. ed. Petrópolis: Vozes, 2008.

COSTA, Marcos Antônio. (2015). "Estruturalismo". In MARTELOTTA, Mário Eduardo (Org). Manual de linguística. 2. ed. São Paulo: Contexto, 2015. p. 113126.

DUBOIS, Jean et all. (1973). Dicionário de linguística. São Paulo: Cultrix, 1973.

FREIRE, Antônio. (1987). Gramática latina. 6 ed. Braga: Livraria Apostolado da Imprensa, 1987.

FURLAN, Oswaldo A; BUSSARELLO, Raulino. (1997). Gramática básica do latim. 3. ed. Florianópolis: Ed. da UFSC, 1997.

GARCIA, Janete Melasso. (2000). Introdução à teoria e prática do latim. 2 ed. Brasília: Ed. UnB, 2000.

KEHDI, Valter. (2007). Morfemas do português. 7 ed. São Paulo: Ática, 2007.

LAROCA, Maria Nazaré de. (2003). Manual de morfologia do português. 3 ed. Campinas: Pontes; Juiz de Fora, MG: UFJF, 2003.

MONTEIRO, José Lemos. (2002). Morfologia Portuguesa. 4 ed. Campinas: Pontes, 2002.

PORTAL DA LÍNGUA PORTUGUESA. Dicionário de termos linguísticos. Disponível em: <http://www.portaldalinguaportuguesa.org/?action=terminology\&act=view\&id=1 669 >. Acesso em: 26 de ago. 2018. 